\title{
XLVI. An account of experiments made at constantinople on Drummond's light, for the purpose of lighthouse illumination in the Black Sea
}

\section{W.H. Barlow Esq.}

To cite this article: W.H. Barlow Esq. (1836) XLVI. An account of experiments made at constantinople on Drummond's light, for the purpose of lighthouse illumination in the Black Sea, Philosophical Magazine Series 3, 8:46, 238-242, DOI: 10.1080/14786443608648855

To link to this article: http://dx.doi.org/10.1080/14786443608648855

曲 Published online: 01 Jun 2009.

Submit your article to this journal $[\pi$

山 Article views: 3

View related articles 
XLVI. An Account of Experiments made at Constantinople on Drummond's Light, for the purpose of Lighthouse Illumination in the Black Sea. By W. H. BarLow, Esq., Civil Engineer. Communicated by P. Barlow, Esq., F.R.S., in a Letter to the Editors of the Lond. and Edinb. Philosophical Magazine and Journal of Science.

Gentlemen, $\quad$ Royal Military Academy, Feb. 4, 1836.

I CAN hardly tell how far the following account of experi1 ments made on Drummond's light at Constantinople may be considered deserving a place in your scientific Journal : it is to me highly interesting, on account of the ingenuity and perseverance it displays in the pursuit of a scientific object, under very difficult circumstances; and $I$ think that it must be gratifying to scientific men generally to know that the Turks, hitherto so bigoted to old maxims and religious prejudices, are availing themselves of the most refined discoveries of modern philosophy.

It may be well to state, as introductory to the following letter, that Mr. W. H. Barlow has been a resident for some time in Constantinople, for the purpose of constructing a brassfoundery and boring-apparatus, upon a large scale, with a view of remodelling the Turkish artillery; and that on the return of Namik Pasha from this country, (who had examined with a scrutinizing eye many of our manufacturing and scientific establishments, ) Halil Pasha, the sultan's son-in-law, sent for Mr. Barlow, and spoke to him on the subject of restoring some dilapidated lighthouses in the Black Sea, and requested to know if he was acquainted with a very remarkable light which was known in England under the name of Drummond's lamp. He was answered that he knew of it generally, and that if he could find any description of it in any of his books, he would furnish him with the particulars. Fortunately, on referring to an ingenious Armenian physician, Dr. Zohrab, who had studied at Edinburgh, he fell upon a number of the Nautical Gazette in which an account was given of the light, and on the ground of the information thus obtained the experiments detailed in the following letter were undertaken.

I am, dear Sirs, yours very truly,

Peter Barlow.

Letter to Peter Barlow, Esq.

Constantinople, Jan. 6, 1836.

"I have already informed you of my first experiments on Drummond's light, and the astonishment it produced in the 
Turks when it first shone forth in all its brilliancy. 'Mashallah allah gunez boo!' was heard on all sides, and I must acknowledge that my astonishment and delight were no less when I first found my attempts successful, in which Dr. Zohrab equally participated, neither of us having ever seen it in England. I promised you that on my return from examining and reporting on the state of the lighthouses in the Black Sea, I would give you a detailed account of my proceedings, a promise which I now propose to redeem as far as the extent of a letter will permit.

"When Halil Pasha first mentioned the Drummond's light, having searched my own library in vain for any description, I applied to Dr. Zohrab, who, having studied in Edinburgh, and being in the habit of reading English works, I thought might possess the desired information; and fortunately he had a number of the Nautical Gazette in which was given several particulars of the light, with drawings, and as we were reading of its beauties, a sudden thought struck us of trying to make it. I set to work that night, and made a drawing of the simplest apparatus I could conceive capable of producing the desired effect, which was as follows. In fig. $1, A$ and $B$ are two bladders, one containing oxygen, the other hydrogen. $C$ is the mixingbox, to which they are attached by being firmly tied upon the two projectFig. 1. ing pipes. In this box were placed about thirty pieces of wire gauze, which, by the by, we were sadly at a loss to obtain till we accidentally fell upon two wire-gauze masks which had been used at the last carnival; these were instantly cut up and arranged in the mixing-box, at the upper end of which we attached the small pipe and stopcock as in the figure. The stopcock belonged to an apparatus of Dr. Zohrab's, and the small pipe was made by an ingenious Armenian at Galeta. Thus prepared, we filled the bladders with the proper gases (after only one unsuccessful attempt), and a piece of lime placed on a lump of clay was put before the jet: a board was then placed on the bladders with a weight on it. We then lighted the jet, and to our inexpressible joy a light instantly burst forth so intense that it was impossible to look directly at it. This being accomplished, and our apparatus appearing safe, I determined to exhibit the light itself to the Pasha, instead of the drawing of it which I had promised him. The astonishment and approbation were, as I have stated, very great, and I was immediately dispatched to the Black Sea, to 
examine and report on the state of the lighthouses. On my return I was requested to make a larger and more complete apparatus, in which I have succeeded to the full extent of my expectation. This last light burns for an hour; it is described below; but $I$ must here first mention a circumstance attending our first exhibition. After this was over, Dr. Zohrab and myself removed our apparatus, and there being still some gas in the bladders, we lighted it again for our own amusement in my drawing-office, when it exploded with great violence while I was pressing the bladders with my hands. You remember the explosion of my gases in my little room at Rushgrove Cottage, but that was nothing; this was so sharp that I lost the sensibility of my right ear for nearly a month, and the explosion forced pieces of the bladders quite through the cloth of my trowsers; and yet, excepting my ear, I escaped without injury.

In my large lamp it was necessary to have recourse to gasometers instead of bladders. These, according to Drummond's description, were to act under a pressure of 30 inches of water; and our explosion had taught us that this pressure must be very equable to prevent the mixing of the gases in any great quantity. Many were the schemes I had, and rejected, but at last $I$ adopted the following:-A, fig. 2 , is a cylinder of tin two feet in diameter, and four feet six inches high, closed at the bottom, and open at the top; B is another cylinder, one foot nine inches in diameter, of the same height, having a diaphragm at one foot eight inches from the bottom; this formed the hydrogen gasometer, and was used as follows: From the bottom of the larger cylinder rose a pipe $D$, to the

Fig. 2.

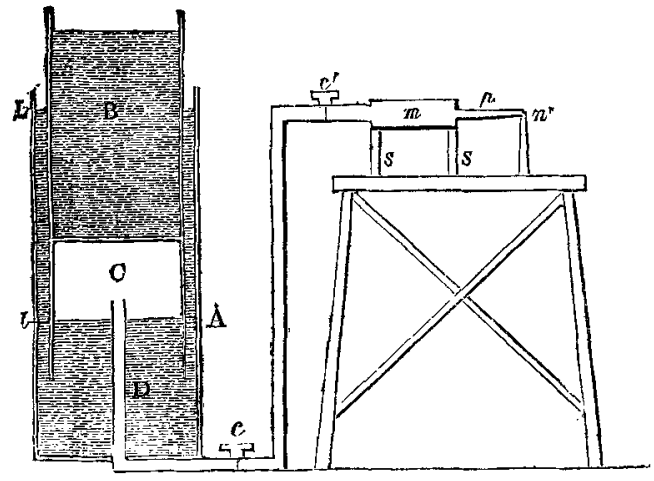

height of one foot nine inches, and a small recess was made 
an inch deep in the diaphragm of the inner cylinder to receive its end; the inner cylinder, therefore, being placed within the other, its edge rested on the bottom of the latter. To fill the gasometer, the interior cylinder was taken out, and water poured into the other to the level $l$; the former was then replaced, the stopcock $c$ opened, and the air expelled till the diaphragm reached the surface of the water; the gas was now introduced at the stopcock, and the gasometer thereby raised: twenty-seven inches of water were now poured into the part $B$, which, together with the weight of the tin, made up the whole pressure of thirty inches. This forced part of the water in $D$ up the sides of the vessel, and other water was added till the external water rose to the level $\mathrm{L}$, which is twenty-nine inches above the top of the pipe; and consequently restored the water in the lower part of the gasometer to its original level $l$. It is now evident that as many inches of gas as are let off are supplied by the upper part descending; and the surface of the upper and lower diameter being the same, the level of the water at $l$ and $\mathrm{L}$ always remained the same, and consequently the pressure. There is, moreover, very little friction, and the action is soft and equal. The oxygen gasometer was constructed in the same manner; but being only required to hold half the quantity, its area of bottom was made only half the former, the height being the same. The other parts are easily comprehended : $c^{\prime}$ is another cock; $m$, the mixing-box ; $s, s$, its supports; $p$, the emission pipe; and $n^{\prime}$, the lime-ball. Fig. 3 is a plan of the whole, showing both gasometers. The mixing-box is made by soldering the pipe $m$ into the outer pipe $n$, which has a diaphragm pierced with holes; the part of the pipe $m$ projecting through it has also holes round its side.

The lamp is lighted thus: the hydrogen being let on by

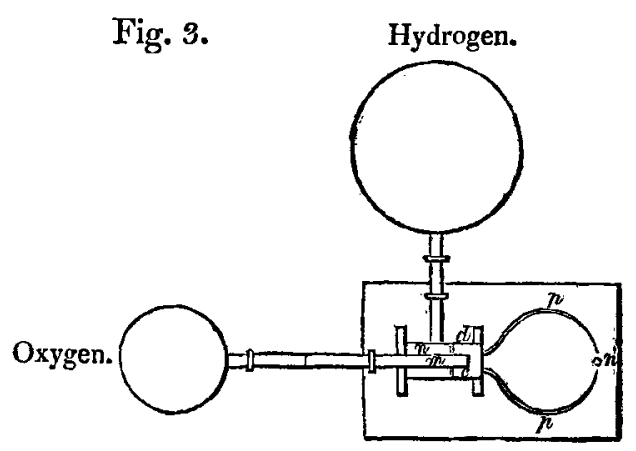

its stopcock being opened, passes into $n$, and through the Third Series. Vol. 8. No. 46. March 1836. 2 C 
diaphragn $d$ into $c$, and passes out through the pipes $p p$; this is now lighted, and it burns with a red unsteady flame; then the oxygen stopcock is turned gradually, when this gas passes through the holes into $c$, where it mixes with the hydrogen, and they come out in perfect union at the pipes $p, p$. The hydrogen cock is now fully opened, and the other cock gradually opened and adjusted till the lime-ball gives out its most brilliant light, when the hydrogen flame entirely disappears.

The difficulties we encountered and the extraordinary shifts we were put to would be very amusing to you, but they are too long for a letter; suffice it to say, that in the end the experiment succeeded beyond our most sanguine expectation. The Pasha was delighted with its performance, and has taken the apparatus to his palace. I have since exhibited to him coal-gas light, which I managed much easier, and have drawn out my estimates for this light and oil; but no doubt the latter will be preferred, and I soon expect to be at work in putting in proper repair the lighthouses of Fanaraki. I an anxiously waiting your further description of Beale's light, which I will also show to the Pasha, who takes great interest in all these matters.

W. H. Barlow.

XLVII. Additional Remarks on the Larw of Magnetic Attractions and Repulsions. By the Rev. WiLliam RITCHIE, LL.D. F.R.S.**

A S Mr. Fox still seems to think that the law of magnetic A attractions is inversely as the distance between the ends of the attracting magnets, without any reference rohatever to their form, the following considerations will, I think, convince him and every impartial inquirer that the supposed law has no existence in nature.

Let two magnets be formed, of plate steel, into the annexed figure, having the poles at $\mathrm{P}, \mathrm{P}^{\prime}$, and consequently further from the ends $a, b$ than if the bar were rectangular; then the attraction between those magnets will follow very different law from that which exists when the bars are equally broad. The fact is, the supposed law obtained by measuring from the ends of the magnet will change with the length of the magnets, their form, and even with the uniformity of the temper.

* Communicated by the Author. 